\title{
Progression of myocardial fibrosis by magnetic resonance imaging in patients with Duchenne and Becker muscular dystrophy
}

\author{
Marly C Silva ${ }^{*}$, Zilda M Meira ${ }^{2}$, Juliana G Giannetti ${ }^{2}$, Marco A Lara ${ }^{1}$, Mariz Vainzof ${ }^{3}$, Mayana Zatz ${ }^{3}$, \\ Roberto Kalil-Filho ${ }^{1}$, Carlos E Rochitte ${ }^{1}$ \\ From 16th Annual SCMR Scientific Sessions \\ San Francisco, CA, USA. 31 January - 3 February 2013
}

\section{Background}

Duchenne (DMD) and Becker (BMD) muscular dystrophy (MD) are inherited X-linked disease characterized by progressive skeletal muscle degeneration and myocardial involvement and caused by a mutation on dystrophin gene (Xp21). Dystrophin is a sarcolemal protein that links the cytoskeleton to the basal lamina and is essential for maintenance of the muscular membrane integrity during muscular contraction. In a previous study, our group described for the first time, in a small group of 10 patients, that CMR can identify myocardial fibrosis (MF) and may be useful for detecting the early stages of cardiomyopathy in MD [1]. The evolution of the myocardial fibrosis over time in this group of patient is still unknown.

\section{Methods}

We enrolled 76 pts, 70 pts with DMD and 6 BMD. Mean age was $13.1 \pm 4.4$ years. 74 patients underwent $2 \mathrm{CMR}$ exams within a mean of 2.3 years, performed on a $1.5-\mathrm{T}$ Siemens Avanto (Erlangen, Germany). Breath-hold LV short-axis and long-axis images were obtained by 2-pulse sequences at the same locations, allowing precise comparisons between LV function (gradient-echo sequence, steady-state free precession) and myocardial structure (inversion-recovery prepared gradient-echo sequence, $10 \mathrm{~min}$ after intravenous bolus or $0.2 \mathrm{mmol} / \mathrm{kg}$ gadolinium-based contrast), acquired with the following parameters, respectively: TR 2.0/ 9.0, TE 1.07/ 5.0; flip angle 69/50; cardiac phases 20/1; VPS 8/16 to 32; matrix $192 \mathrm{x}$ 162 / 256 x 192; ST 8/8 mm; gap 2/2 and FOV 32 to

${ }^{1}$ Cardiology, Heart Institute - InCor, Sao Paulo, Brazil

Full list of author information is available at the end of the article
$38 / 32$ to $38 \mathrm{~cm}$; TI none/150 to $390 \mathrm{~ms}$; receiver bandwidth $930 / 150 \mathrm{~Hz}$; number of excitations $1 / 1$; acquisition every other heartbeat for MDE.

The images were analyzed by two experienced observers. End-systolic LV volume, end-diastolic LV volume and LV ejection fraction were measured by the Simpson method using Argus software, Siemens. For the MDE short axis images, we evaluated the MF mass per patient, using a 5 standard deviation thresholding technique, on a CMR42 software, version 3.4.2 (Circle Cardiovascular Imaging, Calgary, Alberta, Canada). Normal LVEF was defined as above $50 \%$. Test of Wilcoxon was used for comparison of myocardial fibrosis between baseline and follow-up CMR studies.

\section{Results}

Two patients died before the follow-up CMR. For all 74 patients, MF increased significantly from $11.3 \pm 12.2 \mathrm{~g}$ on the baseline CMR to $15.9 \pm 15.4 \mathrm{~g}, \mathrm{p}<0.001$. The number of segments with MF increased from $3.7 \pm 3.3$ to $5.1 \pm 3.6$, $\mathrm{p}<0.001$. In a sub-group with LV dysfunction $(\mathrm{n}=11) \mathrm{MF}$ increased from $26.9 \pm 13.0 \mathrm{~g}$ to $35.5 \pm 20.2 \mathrm{~g}, \mathrm{p}=0.021$. In a sub-group of patients with normal LVEF and no fibrosis $(\mathrm{n}=21)$ on the baseline CMR, MF progressed from $0 \mathrm{~g}$ to $1.5 \pm 3.7 \mathrm{~g}, \mathrm{p}=0.08$.

\section{Conclusions}

Myocardial fibrosis detected by CMR progressively increases in patients with Duchenne and Becker muscular dystrophy over a period of 2.3 years. The progression occurs not only in patients with more advanced cardiomyopathy and LV dysfunction, but also in patients with normal function and no myocardial fibrosis at the baseline CMR. 


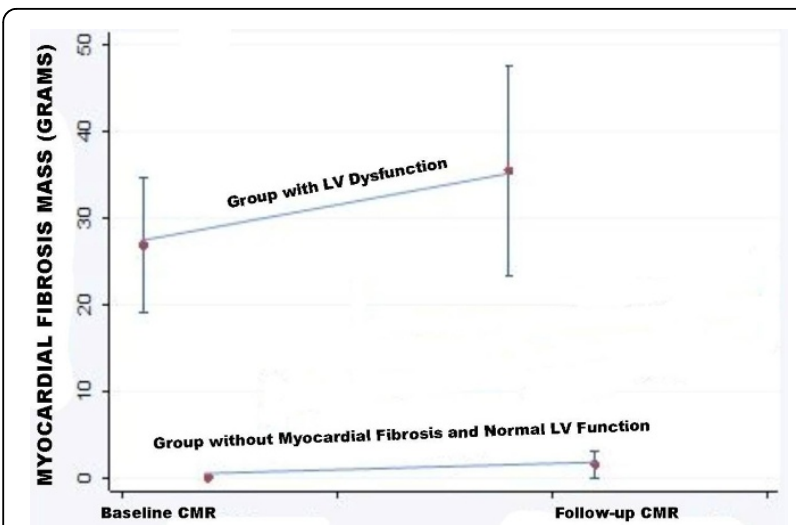

Figure 1 Progression of myocardial fibrosis by CMR between baseline and follow-up for groups with LV dysfunction and without myocardial fibrosis and normal LV function

\section{Funding}

Self Funding.

\section{Author details}

${ }^{1}$ Cardiology, Heart Institute - InCor, Sao Paulo, Brazil. ${ }^{2}$ Federal University of Minas Gerais, Belo Horizonte, Brazil. ${ }^{3}$ Human Genome Research Center,

Bioscience Institute, University of São Paulo, São Paulo, Brazil.

Published: 30 January 2013

\section{Reference}

1. J Am Coll Cardiol 2007, 49:1874-9.

doi:10.1186/1532-429X-15-S1-P148

Cite this article as: Silva et al.: Progression of myocardial fibrosis by magnetic resonance imaging in patients with Duchenne and Becker muscular dystrophy. Journal of Cardiovascular Magnetic Resonance 2013 15(Suppl 1):P148.

\section{Submit your next manuscript to BioMed Central} and take full advantage of:

- Convenient online submission

- Thorough peer review

- No space constraints or color figure charges

- Immediate publication on acceptance

- Inclusion in PubMed, CAS, Scopus and Google Scholar

- Research which is freely available for redistribution

Submit your manuscript at www.biomedcentral.com/submit 